\section{Optimizing Flat Design for Forced-air Cooling of Blueberries Packaged in Plastic Clamshells}

\author{
Jerry C. L eyte ${ }^{1}$ and \\ Charles F. Forney ${ }^{2}$
}

ADDITIONAL INDEX WORDS. precooling, pressure cooling, vent holes, containers, pallet, Vaccinium corymbosum

Summary. Forced-air cooling rates of highbush blueberries (Vaccinium corymbosum L.) packaged in 6-0z (177-mL) or 1-pt (473-mL) clamshell containers were affected by positions of vent holes in corrugated flats. M ost rapid cooling occurred in flats with vents across the top of the flat. Additional vents aligned in front of clamshells resulted in more rapid and uniform cooling than vents placed between clamshells. Vent holes in the bottom of flats had no effect on cooling rates. Clamshells cooled more slowly in the front of the pallet where cold air entered than in the back of the pallet where cold air exited. Fruit in 6-0z clamshells cooled faster than fruit in 1-pt clamshells.

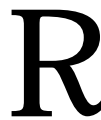

apid removal of field heat from fresh highbush blueberries following harvest is critical to maintain quality and extend storage life. Blueberries store best at $32{ }^{\circ} \mathrm{F}\left(0^{\circ} \mathrm{C}\right)$ and therefore need to be cooled to this temperature as quickly as possible following harvest ( $H$ ardenburg et al., 1986). Delays in

${ }^{1}$ Agricultural engineer, N ova Agri AssociatesL td., Port Williams, N.S. BOP 1T0, Canada.

${ }^{2}$ Storage physiologist, Agriculture and Agri-Food Canada, Atlantic Food and $\mathrm{H}$ orticulture Research Centre, 32 M ain St., Kentville, N .S., B4N 1J 5, Canada.

Contribution 2186. We thank Sherry Fillmore and Brad Walker for assistance in statistical analysis. The cost of publishing this paper was defrayed in part by the payment of page charges. U nder postal regulations, this paper therefore must be hereby marked advertise ment solely to indicate this fact. cooling result in decreased fruit quality and increased decay (H udson and Tietjen, 1981). Room cooling of palletized, packaged fruit is not adequate to prevent quality loss because of slow cooling rates and uneven cooling within the pallet of berries (B oyette, 1996). Forced air cooling enables pallets of fruit to be sufficiently cooled within a few hours with even temperature distribution throughout the pallet improving fruit storagelife(Boyette, 1996).

Recently, plastic clamshells have begun to replace the traditional 1-pt (473-mL) fiber cup containers as the preferred container for packaging berries (Singh, 1991). These containers are available in numerous designs with various arrangements and sizes of vent holes. Also, smaller clamshells are entering the marketplace resulting in many flats of berries holding 24 containers instead of the traditional 12 one-pint containers. The closed nature of the clamshell causes greater restrictions in the contact of cold air with the fruit compared to the traditional open pint basket. Thishas raised questions regarding the optimum flat design for efficient cooling of these containers. Flat design has a strong influence on rates of fruit cooling (Arifin and Chau, 1988; É mond et al., 1994; Talbot et al., 1995). The position of vents on the flat, in relation to the clamshells they hold, may strongly influence the cooling efficiency of the contained product. The objective of

\section{FLAT VENT DESIGNS}

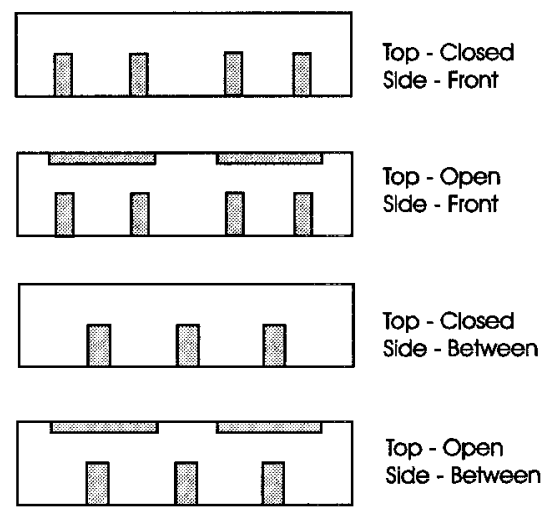

Fig. 1. Patterns of air vents on corrugated cardboard flats used in forced-air cooling study. D rawings represent a side view of the flat's end panel and the shaded areas represent vents. Terminology referring to vent patterns is listed to the right of each design. 
Table 1. T otal percent vent area of corrugated flats that held 24 6-0z (177-mL) or 12 1-pt (473-mL) clamshells. Vents were located across the top of the end panel (closed or open) and/or in front or between clamshells in the flat.

\begin{tabular}{lcccc}
\hline \multicolumn{2}{c}{ Flat vent design } & & \multicolumn{2}{c}{ \% Vented } \\
\cline { 5 - 5 } Top & Side & 6-Ounce & 1-Pint \\
\hline \multirow{2}{*}{ Closed } & Front & 8.1 & 7.7 \\
\multirow{2}{*}{ Open } & Between & 4.6 & 5 \\
& Front & 18.2 & 21.8 \\
& Between & 14.7 & 19.1 \\
\hline
\end{tabular}

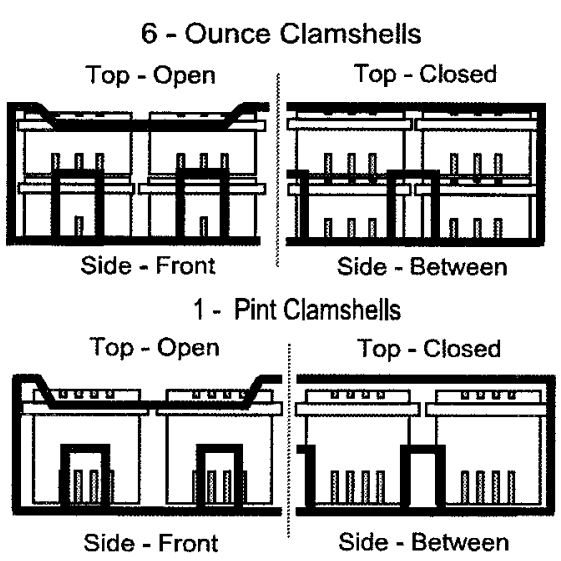

Fig. 2. Orientation of 6-oz (177-mL) and 1-pt (473-mL) clamshells to vents in end panels of cardboard flats. Thick lines represent the outline of flats.

this study was to determine the optimum combination of vent holes in a corrugated cardboard flat that will providerapid and uniform cooling of fresh blueberries throughout a pallet.

\section{Materials and methods}

Forced-air cooling experiments were conducted to compare the cooling rates of berry flats using various vent designs. Theflats' outsidedimensions were $19 \times 13 \times 4$ inches $(48 \times 33$ $\times 10 \mathrm{~cm})$ which held $246-0 z(177-\mathrm{mL})$ clamshells, and $20 \times 15_{3 / 4 \times 3} 1 / 4$ inches $(51 \times 40 \times 8 \mathrm{~cm})$ which held 121 -pt (473-mL) clamshells. Four inlet designs were studied for each flat size, with either a solid or vented bottom (Fig. 1). Vented bottoms consisted of four 1-inch $(2.5-\mathrm{cm})$ diameter holes located 4 inches $(10 \mathrm{~cm})$ from each side. Air vents in the sides of flats were designated as being in front when they aligned with thevents of the clamshells, or between when they were located between the clamshells. Vents located along the top edge of the inlet and outlet sides were designated as top open or top closed. For each flat design, the percent surface area attrib- uted to vents is listed (Table 1). The orientation of clamshells to vents in the flats is shown in Fig. 2. The flats were stacked on a standard $40 \times 48$ inch $(102 \times 122 \mathrm{~cm})$ pallet in a $2 \times 3$ grid, 4 levels high for a total of 24 flats of product (Fig. 3). A commercial pallet of blueberries would have a similar $2 \times 3$ grid with 16 layers of flats. $\mathrm{H}$ eight was scaled down to $1 / 4$ while other dimensions remained full scale for the experimental trials performed. The plastic clamshells used were models 3535-125 (6-0z) and 5040-275 (1-pt), designed and supplied by U Itra Pac Inc. (Rogers, M inn.). The clamshells had air inlets on all sides of the container aswell as on top of thelid (Fig. 4). The clamshells were stacked in a $4 \times 3$ grid with the 6 -oz clamshells two layers high and the 1-pt clamshells a single layer within each cardboard flat.

Cooling experiments were performed in a $32{ }^{\circ} \mathrm{F}\left(0^{\circ} \mathrm{C}\right)$ cold room using a portable precooling fan and plenum constructed at the Kentville Research Centre (Fig. 3). The plenum covered the full width and height of the pallet. The plenum opening had a foam bumper pad on all sidesto create atight seal against the pallet of fruit and to eliminate short-circuiting ofair around the pallet. Air was drawn through the pallet by $a$ 20 -inch (51$\mathrm{cm}$ ) fan driven by a variable speed $1 / 3$ horse Level 3 power motor of $1500 \mathrm{ft}^{3} / \mathrm{min}$ $\left(42.5 \mathrm{~m}^{3} \cdot \mathrm{min}^{-1}\right)$ Level 1 at 0.5 inches $(13$ $\mathrm{mm}$ ) of static pressure (P20T B reezew ay with a capacity Level 2
Panel Fan; PennsylvaniaV entilator C o., Philadelphia).

All testswere conducted between $M$ ay and July 1996, which is before the N ova Scotia highbush blueberry season. Blueberries from the so uthern U.S. were used for measuring the fruit temperature at variouslocationswithin the pallet. Copper-constantan thermocouples, monitored by a data logger (CR7; Campbell Scientific, Logan, $U$ tah), were inserted in the centers of berries to measure the internal fruit temperature during the cooling experiments. A thermocouple and blueberry were placed in the center of 48 selected clamshells filled with dry yellow-eyed beans (Phaseolus vulgaris L.) as a product substituteto createthe necessary air resistance and heat source beforecooling. Yellow-eyed beanswere an economical substitute for blueberries because of their similarity in size. $D$ ifferences in air flow resistance between beans and blueberries may affect absolute cooling rates, but these effects would be relative to treatment effects.

Clamshells without a blueberry and thermocouplealso werefilled with beans. Temperatures were measured in each flat and the position of the flat

Fig. 3. Arrangement of flats on the pallet and their orientation to the fan and plenum for forced air cooling. The top, sides, and bottom of the flats were covered with a plastic tarp. A bumper pad around the plenum opening provided a seal that prevented air from bypassing the flats through the pallet end. The pallet of flats and plenum were located in a cold room held at $32{ }^{\circ} \mathrm{F}\left(0^{\circ} \mathrm{C}\right)$. 


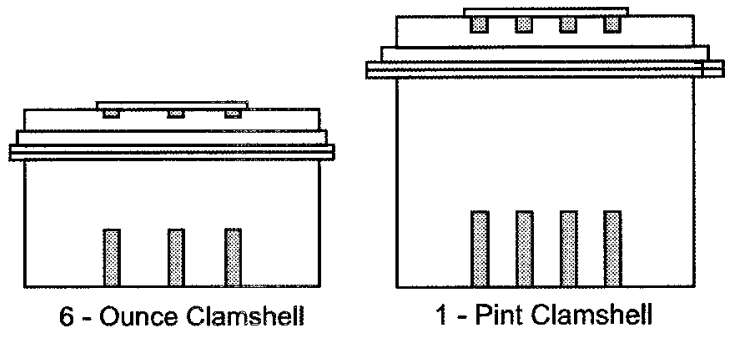

Fig. 4. Design of 6-oz (177-mL) and 1-pt (473-mL) plastic clamshell containers.

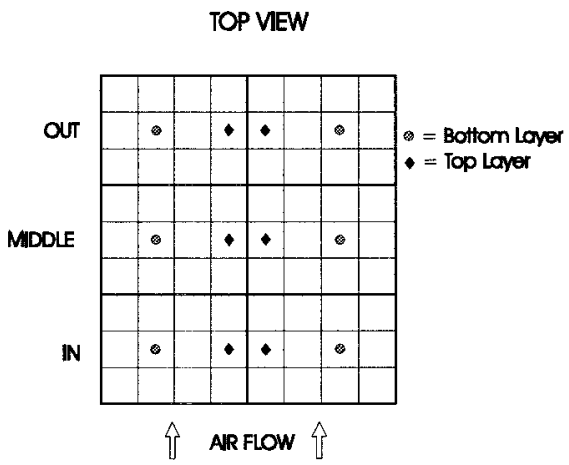

Fig. 5. Position of thermocouples in clamshell containers within each level of flats on the pallet. Thermocouples were located in the center of 6-oz $(177-\mathrm{mL})$ clamshells in the top or bottom layer within the flat or in the middle of the upper (top layer) or lower (bottom layer) third of 1-pt (473-mL) clamshells.

in the $2 \times 3$ grid was designated as the in, middle, or out position in relation to the direction of air flow (Fig. 5). Each flat containing 6-0z clamshells had two layers of clamshells. T wo thermocouples were placed in each flat with onethermocouplelocated in each layer (Fig. 5). In the 1-pt flats the thermocouples were placed in the top or bottom third of each clamshell to keep the thermocouple locations similar to that of the 6-0z. clamshells. T wo flat designsweretested simultaneously with each flat type stacked on one side of the pallet ( $\mathrm{Fig}$. 3). The blueberries were replaced after 2 to $3 d$ to ensure the fruit remained turgid.

Beforecooling, the pallet washeld at room temperature to allow the entirepallet to reach an equilibrium temperature of 59 to $68^{\circ} \mathrm{F}\left(15\right.$ to $20^{\circ} \mathrm{C}$ ). Thermocouples were checked to ensure uniform fruit temperatures prior to being placed in the cold room for cooling. The pallet was placed against the precooler and a plastic tarp was used to cover the top, sides, and bot- tom of the flats resting on the pallet. Cooling air was drawn by the fan through the flats to the fan plenum where it reentered the room. When the precooler was started, a static pressure of 0.5 inches $(1.3 \mathrm{~cm})$ was quickly established using the variable speed fan and an inclined manometer. Thepressuredifferential wasmeasured between the room air and the center of the plenum. The cooling start time was recorded and the temperatures from each thermocouple were logged every 5 min for $\approx 3 \mathrm{~h}$ which was sufficient for calculating the time required to reduce the initial temperature difference between the blueberries and the room air by $7 / 8$ (7/ 8-cooling time).

The experiment was conducted as a $2 \times 2 \times 2 \times 3$ factorial for the $6-0 z$ and 1-pt clamshell flats. There were two levels of top vents(open or closed), two levels of side vents (front or between), two levels of bottom vents (solid or vented), and three levels of position within the pallet (in, middle, or out). The factorial experiment was conducted as a balanced incomplete design over eight runs. Each run included two of the eight flat types with one flat type comprising half of the pallet (Fig. 3). E ach flat type wastested two times. Temperature datafrom each thermocouple were fitted by regression to a logarithmic function using Genstat 5 version 3.2 and the $7 / 8$ cooling times were calculated for each blueberry in which temperature was monitored (Payne et al., 1993). The 7/ 8-cooling times from each flat design and position within the pallet were analyzed using AN O VA and differences between mean values were determined using least significant difference $(P<0.05)$. Experiments using 6-oz and 1-pt clamshells were analyzed separately.

\section{Results and discussion}

The $7 /$ 8-cooling times for all flat designs and for the in, middle, and out locations are shown (Figs. 6 and 7). Fruit in flatswith open topscontaining the 6-oz (177-mL) clamshells cooled $10 \%$ to $40 \%$ faster than those in closed topped flats (Fig. 6). Similarly, fruit in flats with open tops containing 1-pt clamshells cooled $15 \%$ to $55 \%$ faster than those in closed topped flats (Fig. 7). The vent on the top of the flats allowed cold air to be drawn into the vent holes in the top of the clamshells increasing cooling rates. In addition, the vent area of open topped flats was 2.2 to 3.8 times greater than flats with closed tops (Table 1), which may have allowed greater air flow across the fruit resulting in more rapid cooling. $\mathrm{H}$ owever, T al bot et al. (1995) found strawberries in pint clamshells cooled faster in flats with slotted sides and closed tops compared to traditional flats with the open tops. They suggested that flats with top vents channeled air past the fruit and did not cool it as rapidly as when air was drawn through the fruit with side vents. Similarly, Arifin and Chau (1987) found strawberries in 1-pt open baskets cooled $10 \%$ to $20 \%$ faster in flats with side vents and closed to psthan in flatswith solid sides and open tops when vent area was maintained at a constant value (14\%to $18 \%)$. In our study the rapid and even cooling observed in the flats with open tops and vented sides may have resulted from greater vent area and enhanced mixing of cold air throughout the flat.

Position of the vents in the sides of the flats had no significant effect on the cooling rates of the 6 -oz clamshells, however, in the 1-pt clamshell flats, front vents resulted in $10 \%$ to $40 \%$ faster cooling rates than between vents in comparable flats. Vents located in the front position aligned with those of the clamshellsmay bemore effective in drawing air through the fruit than thevents between the clamshells. Vents between the clamshells may result in channeling of air past the fruit resulting in slower cooling rates. Faster cooling of fruit in flats with front venting could also be a result of the one additional vent hole compared to the between flats. This additional vent provided $2.7 \%$ more vent area. In other studies, sidevents that align with vents in thefruit containers resulted in faster, more even cooling than top-vented flats(É mond et al., 1996; T al bot et al., 1995).

Venting the bottom of the flat had no effect on cooling rates of either the 6-0z clamshell flats or the 1-pt clamshell flats (Figs. 6 and 7). Talbot et al. (1995) also observed little difference in the rate of cooling between flats with vented or unvented bottoms. While venting the bottom of flats does not improve cooling rates, these vents may be beneficial to improve air circulation and maintain fruit 


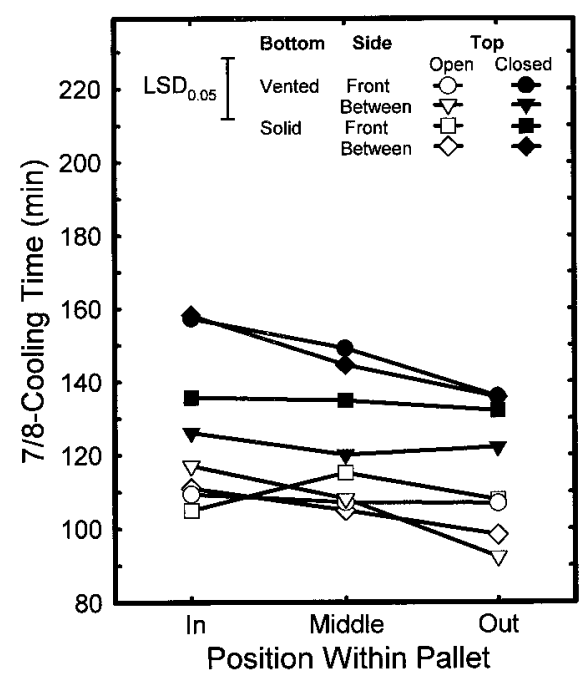

Fig. 6. The 7/8-cooling times of blueberries in 6-0z (177- $\mathrm{mL})$ clamshells at different locations within the pallet and in cardboard flats with different vent hole patterns. Points represent the means of 16 thermocouples. The error bar represents the least significant difference $(P<0.05)$ between means.

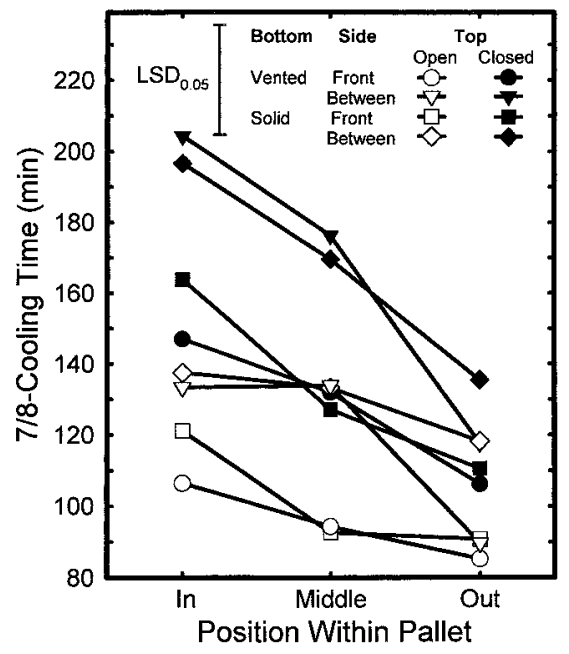

Fig. 7. The 7/8-cooling times of blueberries in 1-pt $(473-\mathrm{mL})$ clamshel Is at different locations within the pallet and in cardboard flats with different vent hole patterns. Points represent the means of 16 thermocouples. The error bar represents the least significant difference ( $P<0.05)$ between means.

temperature during cold storage.

In addition to the flat design, the position of theflat in the pallet affected cooling rates. Fruit cooled slowest in flats where the cold air entered the pallet and fastest in flats where the cold air left the pallet. Differences in cooling rates from the in to the out positions in the 6-0z clamshell flats ranged from 0 to 22 min depending on flat design (Fig. 6). In the 1-pt clamshell flats differences were substantially greater. Flatsin theout position cooled 20 to 70 min faster than flats in the in position (Fig. 7). This slower rate of cooling in the inlet side of the pallet may betheresult of air channeling past the clamshells. As the air penetrates deeper into the pallet, turbulent mixing may increase contact of the cold air with the fruit in the clamshell containers resulting in increased cooling rates. A similar effect wasobserved by E mond et al. (1996), when strawberry fruit in open baskets was cooled in flats with open tops. Fruit cooled moreslowly in the front of the flat than in the middle and they suggested that air flow patterns created a wake which reduced the efficiency of cooling in the first basket of fruit. In other studies using open baskets of strawberries, fruit cooled fastest in the front of the pallet were the air entered and slowest in the back (Arifin and Chau, 1987; É mond et al., 1996).

In general, fruit in 6-oz clamshells cooled more rapidly and more evenly through the pallet than fruit in 1-pt clamshells. D ifferencesin cooling rates were as great as $65 \%$ ( $80 \mathrm{~min}$ ) when comparing 6-0z and 1-pt clamshellsin flats with closed topsand between side vents placed in the front of the pallet where the cold air entered. There were minimal differences in cooling rates of the two clamshell types when they were held in flats with open topsand in front side vents. Talbot et al. (1995) found that strawberries cooled faster in pint than in quart clamshells. The fast cooling rates observed in the small clamshell may be the result of the greater surface area to volume ratio found in the 6-oz clamshells compared to the1-pt clamshells. Thiswould facilitate faster heat exchange between the warm fruit and the cold air. In addition, the greater surface irregularities of the stacked 6-oz clamshells compared to the smooth sides of the 1pt clamshell may have caused greater turbulence, resulting in better mixing of the cold air with the fruit.

An ideal flat design would allow rapid, even cooling of all fruit throughout the pallet. From the results of this study, when cooling blueberries packaged in plastic clamshells, the most rapid, even cooling occurred in flats with open tops and vents positioned in front of the clamshells on the sides of the flats. Flats of this design resulted in $7 / 8$-cooling times of $<120 \mathrm{~min}$ throughout the pallet. Vents in the bottom of the flat were not important for maximizing the cooling efficiency, but could contribute to proper air circulation during cold storage. Although these trials were conducted using dried beansas a filler, the relative rates of cooling in different flat designs should remain the same. H owever, absolute cooling rates may vary if clamshellswerefilled entirely with blueberries due to differences in packing density and thermal properties.

\section{Literature cited}

Arifin, B.B. and K.V. Chau. 1987. Forcedair cooling of strawberries. A mer. Soc. Agr. Eng. M icroficheC ollection Paper 86-6004.

Arifin, B.B. and K.V. Chau. 1988. Cooling of strawberries in cartons with new vent hole designs. Amer. Soc. H eat. Refrig. Aircond. Eng. Trans. 90:1415-1426.

Boyette, M.D. 1996. Forced-air cooling packaged blueberries. Appl. Eng. Agr. 12(2):213-217.

Émond, J.P., M. Bourré, S.O. Sadfa, F. M ercier, and A. G akwaya. 1994. E ffects of airflow patterns on forced-air precooling efficiency of strawberries. Proc. C an. Soc. Agr. Eng. Annu. M tg. 94:318.

Émond, J.P., F. M ercier, S.O. Sadfa, M. Bourré, and A. Gakwaya. 1996. Study of parameters affecting cooling rate and temperature distribution in forced-air precooling on strawberry. Trans. Amer. Soc. Agr. Eng. 39(6):2185-2191.

H ardenburg, R.E., A.E. W atada, and C.Y. Wang. 1986. The commercial storage of fruits, vegetables, and florist and nursery stocks. U SD A Agr. H dbk. 66.

H udson, D.E. and W.H. Tietjen. 1981. Effects of cooling rate on shelf life and decay of highbush blueberries. $\mathrm{H}$ ortScience 16(5):656-657.

Payne, R.W., P.W. Lane, P.G.N. Digby, S.A. H arding, P.K. Leech, G.W. M organ, A.D. Todd, R. Thompson, G.T. Wilson, S.J. Welham, and R.P. White. 1993. Genstat 5 release 3 reference manual. Clarendon Press, Oxford, U.K.

Singh, S.P. 1991. N ew package system for fresh strawberries and raspberries. Amer. Soc. Agr. Eng. Paper 91-6017.

T albot, M .T ., J .K. Brecht, and S.A. Sargent. 1995. Cooling performance evaluation of strawberry containers. Proc. Fla. StateH ort. Soc. 108:258-268. 